\title{
Childhood Unfavorable Prognosis Hodgkin Lymphoma
}

National Cancer Institute

\section{Source}

National Cancer Institute. Childhood Unfavorable Prognosis Hodgkin Lymphoma. NCI

Thesaurus. Code C114808.

A Hodgkin lymphoma with unfavorable prognosis that occurs during childhood. 